Issue $4 / 2017$

\title{
IMPACT OF SUSTAINABLE TOURISM IN THE TRAVEL INDUSTRY
}

\author{
Bogdan SOFRONOV ${ }^{1}$ \\ ${ }^{1}$ University Politehnica of Bucharest, Splaiul Independenței 313, Bucharest, \\ 060042, Romania, Email: bogdansofronov@yahoo.com
}

\begin{abstract}
Sustainable tourism is the concept of visiting a place as a tourist and trying to make only a positive impact on the environment, society and economy. A key aspect is the respect for the people who call the location home, the culture and customs of the area, and the socio-economic system. While sustainable tourism is sometimes confused with ecotourism, ecotourism is actually only one aspect of sustainable tourism.

Sustainable tourism is attempting to have a low impact on the environment and local culture, while also helping to generate future employment for local people. The aim of sustainable tourism is to ensure that development brings a positive experience for local people, tourism companies and the tourists themselves.
\end{abstract}

Keywords: sustainable impact; sustainable tourism; tourism; travel industry; sustainability.

JEL Classification: $\mathrm{Z}_{30}, \mathrm{Z}_{32}$

\section{Introduction}

Sustainable tourism is defined as the development of all forms of tourism, tourism management and marketing that respect the natural, social and economic integrity of the environment, ensuring the exploitation of natural and cultural resources and future generations.

The sustainable tourism covers all forms and activities in the hospitality industry, including conventional table tourism, cultural tourism, business tourism, rural tourism, cruise tourism, religious tourism and sports tourism, urban tourism. The sustainability process should normally be coordinated at national level by governmental stakeholders and supported by local stakeholders at the community level. 

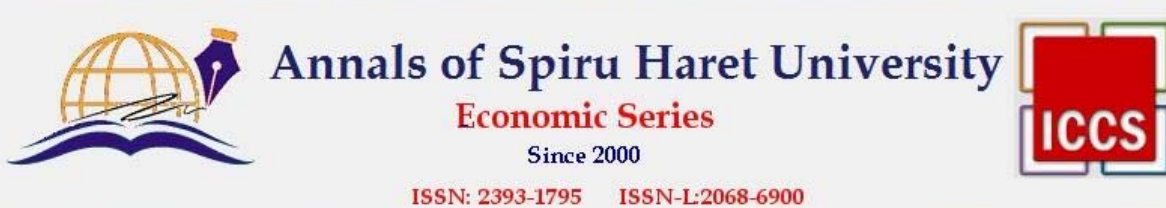

Issue 4/2017

The sustainability in tourism has the following independent aspects: environmental, socio-cultural and economical. Sustainable development implies sustainability, which means that sustainable tourism requires optimal use of resources, minimizing economic, socio-cultural and ecological negative impacts, maximizing benefits for local communities, national economies, and preserving nature. As a natural consequence, sustainability also refers to the managerial structures needed to meet these desires.

In my opinion, the goal of sustainable tourism must be subordinated to national and regional economic and social development plans. Actions can cover economic goals, social goals, poverty alleviation and inequality in income distribution, the protection of indigenous socio-cultural heritage, participation and involvement of local communities, or ecological goals to protect the functions of ecotourism, the conservation and sustainable use of biodiversity. Some specialists prefer to talk about the sustainable development of tourism rather than sustainable tourism, the first referring to all aspects of development, and the second to some aspects and components of tourism - such as long-distance air transport that can purely and simply not be sustainable under current technology, even with the use of best practices.

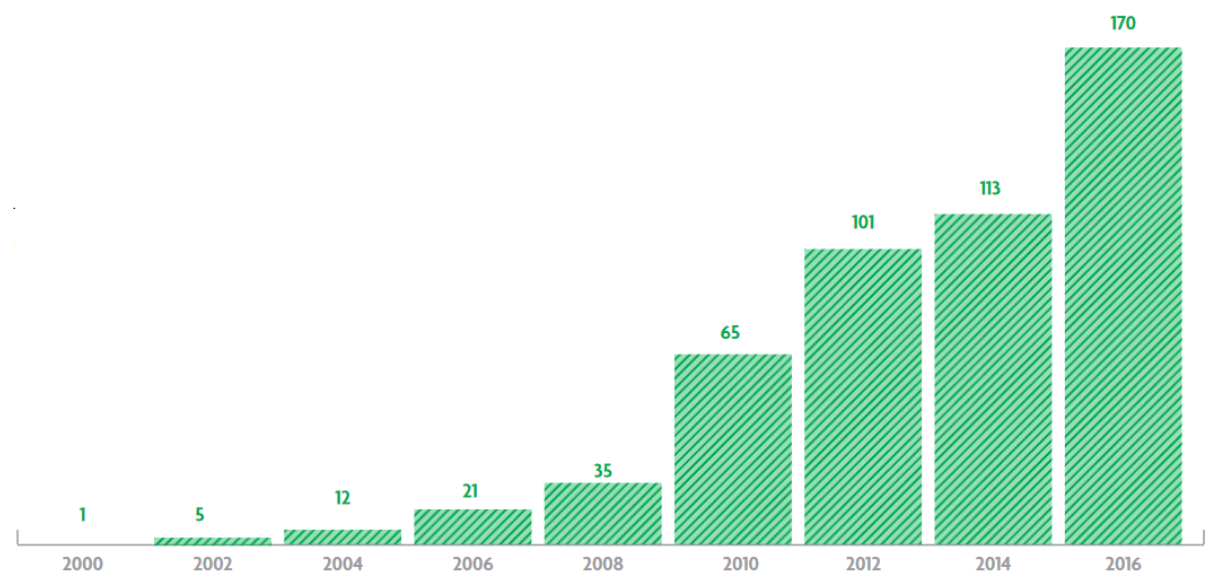

Figure no. 1. Sustainability Reporting within Tourism

Source: Sustainability Reporting in Travel and Tourism (2017), World Travel \& Tourism Council, accessed October 31, 2017, https://www.wttc.org/-/media/files/reports/policyresearch/esg-2017/esg-2017-sustainability-reporting-in-travel-and-tourism.pdf 


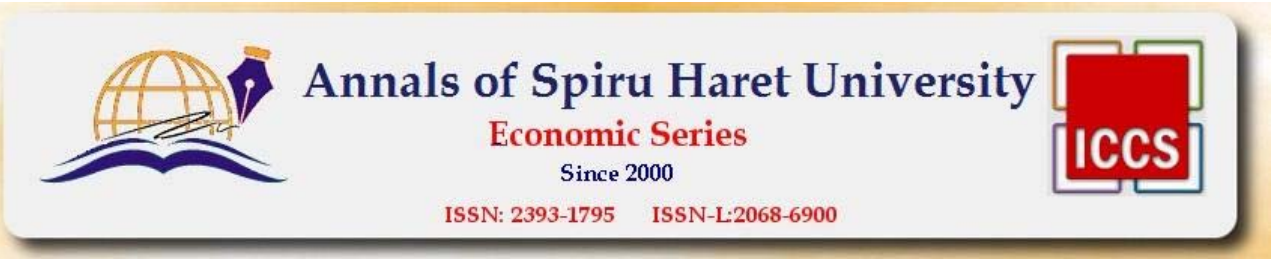

Issue 4/2017

\section{Literature review}

My research paper entitled Impact of sustainable tourism in the travel industry is written after I have documented on the basis of the following published articles:

1. "Sustainable Tourism Research: An Analysis of Papers" written by Jiaying Lu and Sanjay K. Nepal, published in the Journal of Sustainable Tourism.

2. "Sustainable Tourism: A State-of-The-Art Review" written by Richard W. Butler and published in the International Journal of Tourism Space, Place and Environment.

3. "Romanian Tourism Marketing Researches" written by Viorica Jelev and published in the Annals of Spiru Haret University. Economic Series.

\section{Key challenges for more sustainable tourism}

Promoting sustainable tourism is essential, especially in the regions of the world that have experienced the fastest rate of global warming. Therefore, the management of water resources, pollution and waste and the fight against soil erosion are among the major challenges of tourism.

Promoting sustainable tourism requires the reduction of foreign visitors' culture as much as possible, as well as the prevention of excessive marketing of the local culture. It is vital that sustainable tourism allows for the preservation of traditions and does not affect the rich diversity of the region.

Starting from the key points of sustainable tourism development, the impact of tourism activities implies the following:

- increasing the viability of some localities with reduced natural resources;

- the use of poorly productive agricultural land, by developing appropriate tourism facilities;

- increasing the incomes of the inhabitants in the conditions of the reduction of grazing and exploitation forestry;

- increasing the economic power of the localities, by obtaining new revenues from new and local taxes;

- encouraging the traditional activities, especially those of artisanal and small industry traditional;

- developing a specific trade based on local economy and craft products;

- the revenues from tourism and the specific trade of this framework can contribute to supporting the modernization of the cultural objectives, the ecological restoration of the valuable landscapes; 

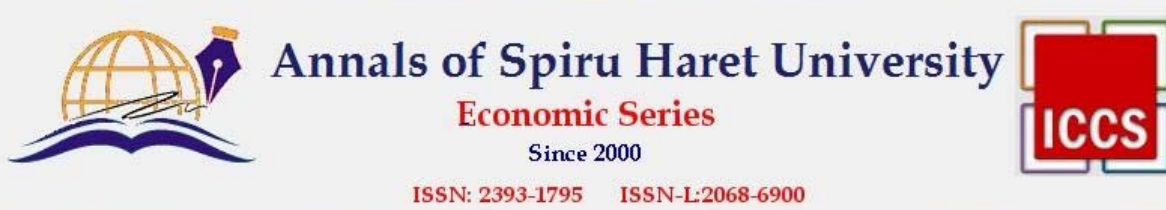

Issue 4/2017

- the profit and earnings port - as a result of the reception, hosting, transport and public catering activities, will be an important contribution to the local development plan.

To have a more sustainable tourism, we need to [Sustainable Tourism, 2017]:

- use biodegradable products for washing, cleaning, protecting local water sources;

- use only sustainable products to build hotels and ensure the wood is from sustainable forests;

- collect rainwater and recycle the water. This is possible in the tropical climates, where there is a large quantity of water;

- set quotas to limit the amount of tourists visiting an area. Establish a carrying capacity and stick to it;

- creating national parks and reservations to protect local flora and fauna;

- creating breeding programs for endangered species e.g. the Amur Leopard or the Panda;

- use renewable energy to power tourist facilities e.g. solar or wind;

- use local food products to reduce food miles;

- transport guests using public transport or low emission vehicles.

To make tourism economically sustainable, we need to [Sustainable Tourism, 2017]:

- secure as much money as possible in the host country, then to minimize economic leakage. Profits from many companies go overseas. This can be a difficult balancing act, because we do not want to stop FDI;

- employ only the local residents in touristic facilities. Train local staff so that they are able to work in managerial positions, as well as other positions. These skills can then become transferable to different local industries;

- be locally owned. This is not always possible, especially if FDI is needed to establish a tourism resort or project, but local staff and products should definitely be used;

- purchase only local products;

- avoid debt when building tourist developments.

The sustainable tourism in urban areas [Sustainable Tourism, 2017]:

- promote local hotels and shops;

- reduce electricity and water waste by educating tourists;

- ensure locals can also afford to visit national historic sites. Many countries run dual pricing, where tourists pay more than locals to visit sites;

- recycling bins; 


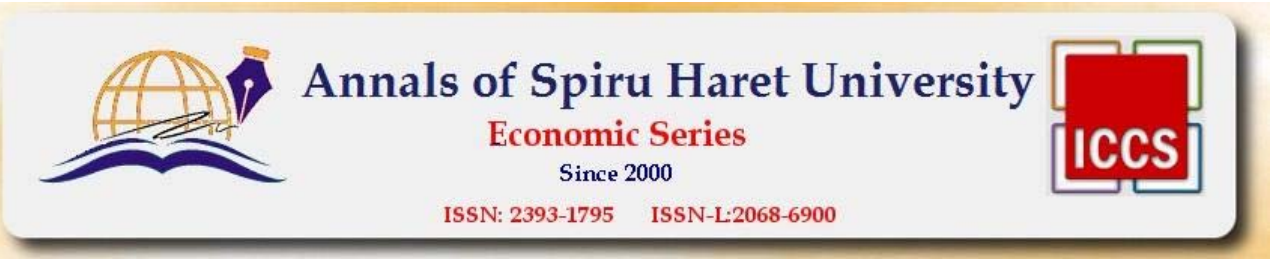

Issue 4/2017

- enforced fines for littering;

- pedestrianised areas;

- cheap public transport;

- bike hire;

- possible introduction of quotas or curfews to protect areas;

- ensure locals are not priced out of the local market - try and maintain traditional mix of residents, tourists, businesses, etc.

The sustainable tourism in coastal environments [Sustainable Tourism, 2017]:

- is important to avoid sewage being pumped into the sea;

- banning of plastic bags very harmful to turtles who mistake them for jellyfish;

- avoid light pollution near turtle nesting sites. Baby turtles are often confused by light and struggle to find the sea (normally they use the light from the horizon);

- promote sustainable diving (possible introduction of quotas like in Sipadan, Malaysia);

- avoid privatisation of beaches. Ensure that locals can also use the beach;

- stop trade in coral, turtles shells, etc.;

- ensure that seafood is caught from sustainable sources. In Japan, sustainable sushi is being introduced to protect blue fin tuna, whales, etc.;

- minimise damage to mangroves, dunes, forests, etc. when building resorts;

- ensure proper boating channels to avoid injury and death to turtles, manatees, etc. from speed boats and jet skis.

The sustainable tourism in national parks [Sustainable Tourism, 2017]:

- is important to create National Parks to protect flora and fauna;

- reforest areas that have been damaged or logged;

- ensure that no illegal logging takes place;

- stop poaching (catching wild animals) by making it illegal and enforcing with strong penalties;

- only allow low impact activities e.g. walking, horse riding;

- start breeding and reintroduction programmes e.g. the giant panda in China;

- only allow small scale developments using locals products to build the small-scale low-impact developments e.g. basic cabins or just tents;

- use renewable energy sources e.g. local HEP;

- ensure no non-biodegradable products are released into local water sources or into the ground; 

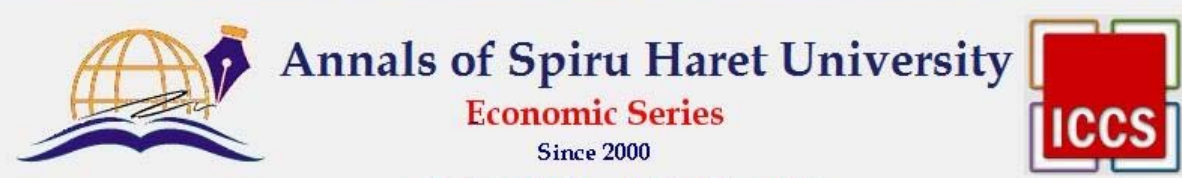

Issue 4/2017

- educate tourists about flora and fauna and the importance of protection.

\section{Impact of sustainable tourism in the travel industry}

The tourism industry is responsible for about $5.3 \%$ of total greenhouse gas emissions, $75 \%$ of which is generated by transport, which is the main source of air pollution related to tourism. Therefore, it is important to promote clean or less energy-efficient modes of transport.

The air transport is by far the most polluting means of transport, but public administration itself often promotes it against rail transport. Every year there has been an annual 5-6\% increase in the number of flights, especially as a result of the significant reduction in ticket prices.

Sustainable tourism has the following principles:

- the tourist activity must be initiated with the own means of the local community, and it must maintain its control over the tourism development;

- tourism must provide jobs to residents to improve the quality of life for the local communities and a balance must be struck between the economic activities already existing in the area and the tourism activity;

- a code of practices for tourism must be established at all levels: national, regional and local, based on already accepted international standards. The guidelines for tourism operators, the monitoring of the impact of different tourist activities and the acceptability limits for different areas can also be established;

- educational and training programs are needed to improve management in the field of natural and cultural resources protection.

So, the sustainable tourism development is not only a concept debated, completed or reformulated in the conferences held on this topic. The need to protect the natural, social and cultural richness that constitutes the common heritage of humanity and the satisfaction of the needs of the tourists and the local population has led to the emergence of sustainable forms of tourism. The objectives, principles and requirements of sustainable tourism development are found in forms of tourism such as ecotourism, rural tourism or cultural tourism. These forms are the expression of the desire for tourism to represent not only a positive and dynamic development factor, but also a practical solution for the unaltered preservation of the environment.

\section{Critical issues for the future of sustainable tourism}

These critical issues are the following: developing of sustainable tourism through its practical forms, reconciling antagonistic interests and objectives, fostering 

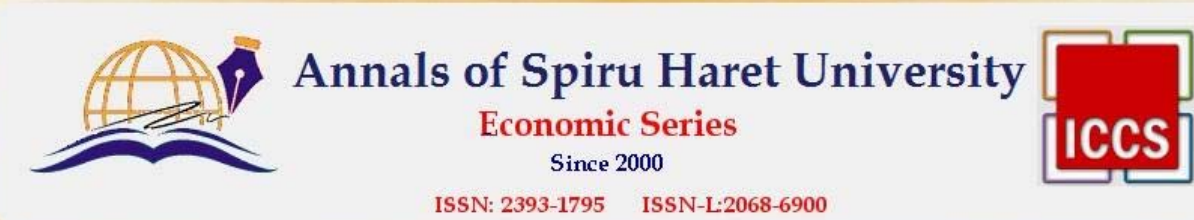

SSN: 2393-1795 ISSN-I-2068-6900

Issue $4 / 2017$

partnership and cooperation among decision-makers, operators and consumers and promoting long-term general interest.

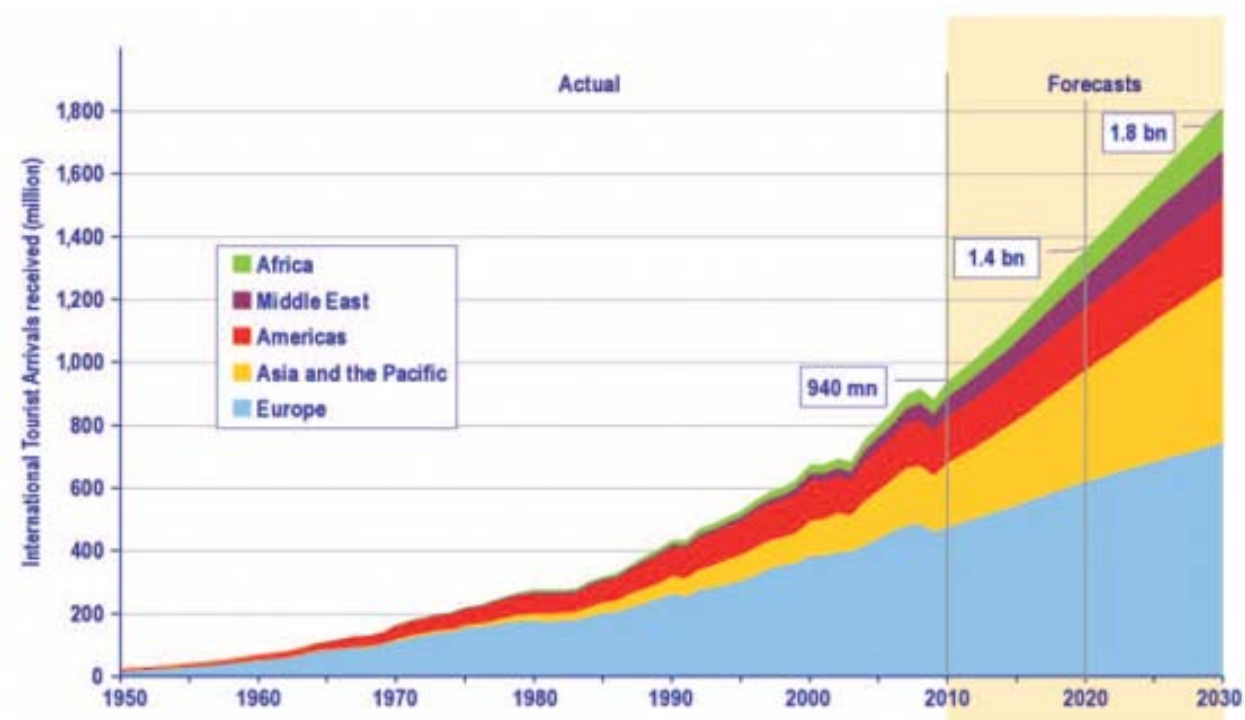

Figure no. 2. UNWTO Tourism Towards 2030: Actual trend and forecast 1950-2030

Source: Gaval, I. (October 6, 2016), The Economic Benefits of Sustainable Tourism, accessed October 31, 2017, https://ecobnb.com/blog/2016/10/economic-benefitssustainable-tourism/

The tourism industry gives a greater importance to environmental issues and increasing attention to sustainable tourism, the differences between good intentions expressed by people when undergoing research and what they will actually do on holidays should not be underestimated. There is no doubt that tourism, if wellplanned and driven, can generate income for the local population and speed up the development of the region. It has become a major source for many countries around the world. World, cultural and natural heritage, for example, attracts visitors from all over the world and can become the engine of local development. But more attention should be paid to the physical and cultural impact of mass tourism, including indirect losses arising where overcrowding occurs. 


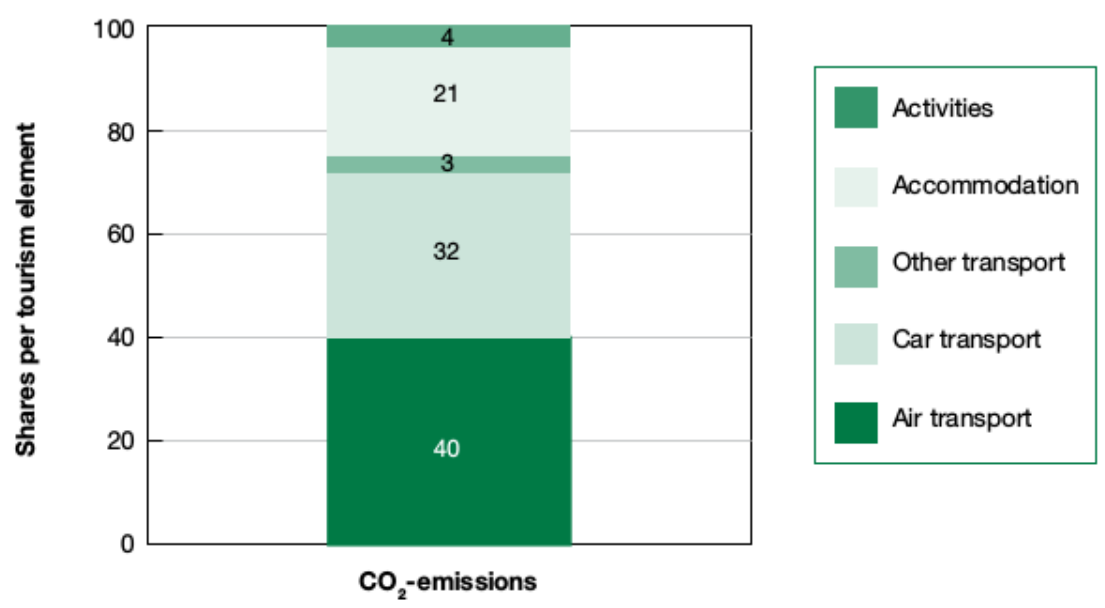

\section{Figure no. 3. Contribution of various tourism sub-sectors}

to $\mathrm{CO}_{2}$ emissions (\%)

Source: Gaval, I. (October 6, 2016), The Economic Benefits of Sustainable Tourism, accessed October 31, 2017, https://ecobnb.com/blog/2016/10/economic-benefits-

sustainable-tourism/

The future of sustainable development depends on the restructuring of the global economy and requires major changes in human behaviour, value system and lifestyle. We can no longer claim that tourism is one of the best ways to achieve local sustainable development when it is rather the bitter-bitter antidote of sustainable development from anywhere. World, cultural and natural world should be used as best to sensitize people in terms of the importance of building links between nature and culture, between different cultures.

\section{Conclusions}

In conclusion, the sustainability and competitiveness of the tourism industry go hand-in-hand as the quality of tourist destinations is strongly influenced by their natural and cultural environment, and their integration into the local community. [Sustainable Tourism, EC, 2017]

Sustainability in tourism on long-term requires a balance between economic, socio-cultural, and environmental sustainability. The need to reconcile economic 

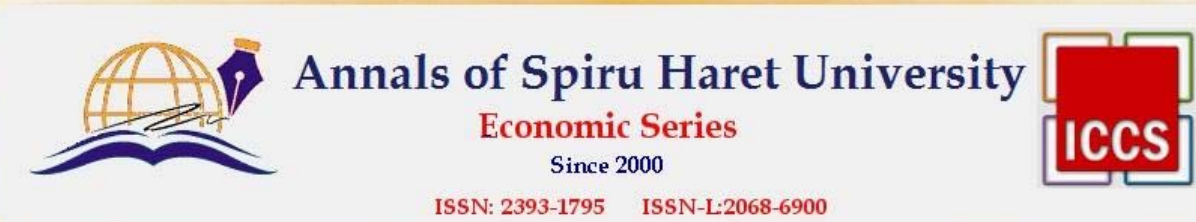

ISS: $2393-1795$ ISSN-I-2068-6900

Issue $4 / 2017$

growth and sustainable development also has an ethical dimension. [Sustainable Tourism, EC, 2017]

\begin{tabular}{lll} 
& Overall Universe & $\begin{array}{l}\text { Overall Universe } \\
\text { Reporters }\end{array}$ \\
\hline Set a GHG Target & $11 \%$ & $46 \%$ \\
\hline Set an Energy Target & $9 \%$ & $36 \%$ \\
\hline Set a Water Target & $6 \%$ & $26 \%$
\end{tabular}

Figure no. 4. Prevalence of energy, water, waste, and carbon targets in travel \& tourism

Source: "Sustainability Reporting in Travel and Tourism,” World Travel \& Tourism Council, accessed October 31, 2017, https://www.wttc.org/-/media/files/reports/policyresearch/esg-2017/esg-2017-sustainability-reporting-in-travel-and-tourism.pdf

The most significant challenges for sustainable tourism are [Sustainable Tourism, EC, 2017]:

- improving the quality of tourism jobs;

- preserving natural and cultural resources;

- limiting negative impacts at tourist destinations, including the use of natural resources and waste production;

- promoting the wellbeing of the local community;

- reducing the seasonality of demand;

- limiting the environmental impact of tourism-related transport;

- to make tourism accessible to all.

The development of sustainable tourism is based on the following:

- setting ecological limits, consumption standards and norms, reducing unjustified consumption;

- redistribution of economic activity and reallocation of resources, satisfaction of the essential needs of life, and at the same time economic growth;

- providing a optimal population, the demographic increase being in line with the potential of the exploitable ecosystems; 

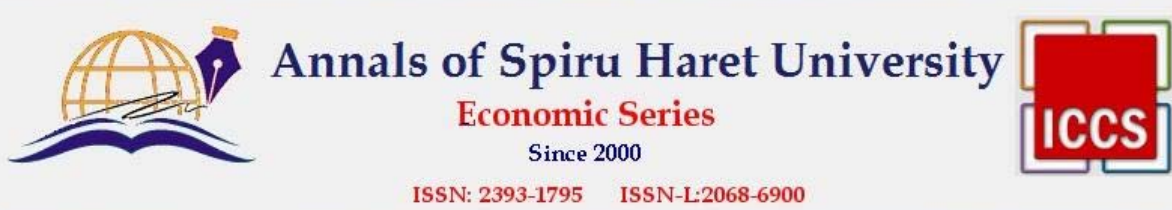

ISSN: 2393-1795 ISSN-L:2068-6900

Issue 4/2017

- conservation of basic resources and preservation of natural areas that support the genetic patrimony of flora and fauna;

- legal access to resources, increased technological effort and rational use;

- the establishment of a minimum rate of exploitation and resource consumption;

- community control, the role of the local community in the decision-making of local development;

- ensuring the management of all resources that emphasize quality.

The positive aspects of sustainable tourism are:

- increase the social and professional chances by creating new jobs, tourist services and general infrastructure;

- create new seasonal jobs, especially for young people and women;

- developing and ensuring social progress, increasing the cleanliness and public hygiene, general comfort in the tourist localities;

- decreasing the differences between socio-professional categories in terms of income;

- developing feelings of understanding and tolerance because intercultural exchanges between tourists and the host population facilitate the disappearance of linguistic, social, racial, religious and cultural barriers.

\section{References}

1. Gaval, I. (October 6, 2016), Retrieved from https://ecobnb.com/blog/2016/10/economicbenefits-sustainable-tourism/

2. Sustainability Reporting in Travel and Tourism, (October, 2017), retrieved from https://www.wttc.org/-/media/files/reports/policy-research/esg-2017/esg-2017sustainability-reporting-in-travel-and-tourism.pdf

3. Sustainable Tourism (2017), accessed November 1, 2017, http://greenfieldgeography.wikispaces.com/Sustainable+tourism

4. Sustainable Tourism, European Commission (2017), accessed November 1, 2017, https://ec.europa.eu/growth/sectors/tourism/offer/sustainable_en 